\title{
Psychological Risk Factors for the Development of Stroke in the Elderly
}

\section{Atsushi Araki* and Hideki Ito}

Department of Diabetes, Metabolism, and Endocrinology, Tokyo Metropolitan Geriatric Hospital, Japan

\begin{abstract}
The increased risk of stroke with old age cannot be entirely explained by conventional risk factors, such as hypertension, diabetes, smoking, and hyperlipidemia. Incident stroke has also been associated with depression, other negative feelings, or stressors, like life events, disabilities, and earthquakes; in contrast, protective psychological factors against stressors that include optimism, positive coping style, positive attitude toward aging, and a sense of coherence have been associated with a reduced incidence of stroke. Thus, enhancing protective psychological factors may be an advantageous approach to preventing the development of stroke. However, further studies are necessary to understand the mechanism by which psychological factors influence the risk of stroke and atherosclerosis. Sense of coherence reflects the ability to cope with psychological stress and to tailor life style choices for the promotion of health; thus, improving an individual's sense of coherence could impact on their life-style choices such as exercise, diet, and psychological approaches to stress, which in turn may contribute towards the prevention of stroke in the elderly.
\end{abstract}

Keywords: Stroke; Depression; Sense of coherence; Life-style intervention; Psychological approach

Abbreviations: HR: Hazard Ratio; CI: Confidence Interval; CES-D The Center for Epidemiologic Studies Depression Scale; BDNF: BrainDerived Neurotrophic Factor; TIA: Transient Ischemic Attack; ADL: Activities of Daily Livings; HbAlc: Hemoglobin A1c; HDL: High Density Lipoprotein; IMT: Intima Media Thickness; BMI: Body Mass Index; IL-6: Interleukin-6; IL-1: Interleukin-1

\section{Introduction}

Although recent remarkable advances have been made with regard to the treatment of hypertension, hyperlipidemia, and diabetes, the incidence of stroke, and in particular ischemic stroke, in elderly individuals has not been decreased to any great extent. It is well known that aging or age-related circumstances is one of the most important risk factors for stroke [1]; however, the increased risk of stroke with old age cannot be entirely explained by conventional risk factors, such as hypertension, diabetes, smoking, and hyperlipidemia [2].

The psychological state of elderly individuals is affected by life events, physical and mental functions, co-morbidity and related treatment, loneliness, social support, social participation, and economic status. Depression also increases with age, which in turn can lead to poor quality of life and suicidal tendencies [3].

Although psychological factors such as work stress and type A behavior have been reported as a predictor of stroke in young people [4,5], different psychological states may come into play when considering the incidence of stroke in the elderly. We have previously demonstrated that feelings of low well-being, as assessed using the Philadelphia Geriatric Center (PGC) Morale Scale, was an independent predictor of stroke in elderly diabetic patients [6]. Interestingly, a positive attitude towards aging, as a subscale of the moral scale, was associated with a low incidence of stroke.

In this article, we would like to review the psychological factors involved in the development of stroke in elderly individuals.

\section{Stressors and Stroke}

Older people tend to be exposed to stressors, such as life events, functional disabilities, and comorbidity. Kornerup et al. demonstrated that the accumulation of life events is associated with an increased risk of stroke (HR=1.41; 95\% CI, 1.06-1.90) compared to that of one event [7]; moreover, they reported that major life events accumulated over a life course displays a dose-response relationship with stroke. It has also been demonstrated that recent stressful life events are linked to incident stroke within a month of the event occurring [8]; indeed, patients exposed to more than one life event preceding this month were more likely to develop stroke than during the control period (odds ratio $=2 \cdot 96 ; 95 \%$ CI, 2.19-4.00).

Earthquakes have also been associated with incident stroke. In the Hanshin-Awaji earthquake, stroke incidence increased in the first year following the earthquake compared to the year before ( $\mathrm{HR}=2.4 ; 95 \%$ CI, 1.1-5.0) [9]. Furthermore, the earthquake intensity in different districts was associated with increased incidence of stroke. This may be explained by the fact that earthquakes increase blood coagulation and blood pressure, which in turn may lead to cardiovascular disease [10]; increased blood glucose as a result of the disaster is also a risk factor for stroke [11].

Socioeconomic status may affect incidence and mortality of stroke as a stressor [12-14]. People with low socioeconomic status have a high incidence of stroke, more risk factors, and high rates of stroke mortality as compared with high socioeconomic people [13]. Lazzarino et al. demonstrated that low economic status and psychological distress had synergistic effects on incident mortality from stroke in a prospective study of the Health Survey for England [14]. In fact, the overall stroke incidence rates in low to middle income countries have exceeded the level of stroke incidence in high-income countries by $20 \%$ in $2000-2008$ [15].

*Corresponding author: Atsushi Araki, Department of Diabetes, Metabolism, and Endocrinology, Tokyo Metropolitan Geriatric Hospital, Japan, Tel: +81-3-39641141; Fax: +81-3-3964-1982; E-mail: aaraki@tmghig.jp

Received February 16, 2013; Accepted March 30, 2013; Published April 07, 2013

Citation: Araki A, Ito H (2013) Psychological Risk Factors for the Development of Stroke in the Elderly. J Neurol Neurophysiol 4: 147. doi:10.4172/21559562.1000147

Copyright: $\odot 2013$ Araki A, et al. This is an open-access article distributed under the terms of the Creative Commons Attribution License, which permits unrestricted use, distribution, and reproduction in any medium, provided the original author and source are credited. 


\section{Depression and Stroke}

In several epidemiological studies, depressive symptoms have been associated with an increased incidence of stroke [16-18]. Depressive disorder is also a risk factor for stroke independent of traditional cardiovascular risk factors $[19,20]$. In the Baltimore epidemiologic catchment area study comprised of 1703 participants, individuals with a history of depressive disorder were 2.6 times more likely to have a stroke compared to those without the disorder, even after controlling for conventional risk factors during the 13-year follow-up period [19]. In the Nurses' Health Study, it was reported that depression (physician-diagnosed depression or Mental Health Index score $\leq 52$ ) in 80,574 women aged between 54 and 79 years, as well as the use of antidepressant medication, was associated with an increased risk of stroke [20]. In a prospective cohort study of 14,784 adults (aged 52.4 \pm 11.9 years), it was reported that the use of tricyclic antidepressants was associated with an elevated risk of stroke (HR=1.35; 95\% CI, 1.031.77), while the use of SSRIs was not associated with stroke [21].

Both depressive symptoms, as assessed by the CES-D, as well as a lifetime history of depression also predicted poor functional outcomes and poor quality of life in patients with stroke [22].

Interestingly, the presence of cardiac disease reportedly increases the association between depressive symptoms and incident stroke [23]; in this study, both the severity and chronicity of depressive symptoms during follow-up were associated with an increased risk of stroke in patients with cardiac disease. In a sample of women with suspected myocardial ischemia, subjects with smaller social networks were more likely to possess depressive symptoms and develop stroke at a rate greater than twice that of individuals with more social relationships after adjusting for covariates $(\mathrm{HR}=2.7 ; 95 \% \mathrm{Cl}, 1.1-6.7)$ [24].

In the Established Populations for Epidemiologic Studies of the Elderly (EPESE) study, low education and income in individuals aged between 65 and 74 years were associated with a higher incidence of stroke [25]. Since the association between socioeconomic status and stroke were attenuated when adjusted for race, diabetes, depression, social networks, and functioning, social-psychological interaction may contribute to the development of stroke in the elderly.

Genetic factors may affect the association between depressive symptoms and stroke. For example, it was demonstrated that the association between incident stroke and depression increased with the numbers of met alleles of the BDNF polymorphism [26].

\section{Negative Feelings other than Depression and Stroke or Atherosclerosis}

Surtees et al. demonstrated that psychological distress, but not major episodic depressive disorder, was associated with an increased risk of stroke [27]. In a large population-based prospective study using 20,627 stroke-free participants, aged 41-80 years, a 1-SD decrease in Mental Health Inventory-5 scale score (representing greater emotional distress) was associated with an $11 \%$ increase in stroke risk, after adjustment of covariates [27]. In a prospective observational study of 2201 men aged 45-59 years, psychological distress, defined by a score of $\geq 5$ on the 30 -item General Health Questionnaire, was a predictor of fatal ischemic stroke but not of nonfatal ischemic stroke or TIA [28].

Feeling of low well-being also affects incident stroke in patients with diabetes mellitus [6]. Diabetes mellitus is associated with an increased incidence of geriatric syndromes: functional disabilities, depression, fall, urinary incontinence, and cognitive impairment, all of which act as stressors [29]. Diabetic patients have a variety of psychological problems, such as depression, low well-being, emotional distress, and diabetes-specific burden [30-33]. Low well-being in older diabetic patients is associated with low $\mathrm{ADL}$, macrovascular complications, insulin treatment, hypoglycemia, negative social support, lack of positive support, and low economical satisfaction [31-33]. In our 3 -year follow-up study of 376 diabetic patients free of stroke and with a mean age of 75 years, low well-being, as assessed with a PGC morale score of $\leq 7$, was a significant predictor of stroke after adjusting for age, gender, body mass index, HbAlc level, systolic blood pressure, serum levels of total cholesterol, triglycerides, HDL-cholesterol, smoking, and history of ischemic heart disease (HR=3.0; 95\% CI, 1.2-7.3) [6]. Increased symptom burden of the Elderly Burden Diabetes Scale was also a significant predictor for stroke after these covariates. In patients with drug-treated hypertension, low contentment and low vitality, as assessed using the Minor Symptoms Evaluation Profile, predicted incident stroke after adjusting for potential cardiovascular risk factors [34].

Negative feelings of discontent, hopelessness, hostility, and anger have been associated with subclinical carotid atherosclerosis [35-39]; high levels of hopelessness were associated with carotid IMT after adjusting for depressive symptoms and conventional risk factors [36]. In middle-aged women, high scorers of hostility, indicated by the 13 item questionnaire $(\geq 6)$, had a greater mean and maximum carotid IMT compared to low scorers [37]. In a population study of 6561 men and women aged 45-84 years, the trait anger score was positively associated with carotid IMT and the presence of carotid plaques [38].

However, despite these findings, several other studies have showed that the association between depressive symptoms and carotid atherosclerosis are inconsistent $[36,38-40]$. Some difficulties in accurate measurement of depressive mood and other negative feelings because of lack of validity may explain the inconsistent results. Alternatively, the mechanism by which atherosclerosis and stroke develop in association with depression or negative feelings might be different.

\section{Protective Psychological Factors}

Protective psychological factors against stressors, including optimism, low pessimism, positive coping style, positive attitude towards aging, and a sense of coherence are important for the prevention of stroke. In the Health and Retirement Study of 6044 adults, aged $>50$ years, who were stroke-free at baseline and followedup for 2 years, higher optimism was associated with a lower risk of stroke after adjusting for sociodemographic, behavioral, biological, and psychological risk factors [41]. In contrast, in a 7-year follow-up study of 23,216 adults aged 20-54 years, participants with the lowest quartile of pessimism had a reduced incidence of stroke compared to those with the highest quartile, after adjusting for sociodemographic characteristics, bio-behavioral risk factors, depression, general feeling of stressfulness, and ischemic heart disease (HR=0.52; 95\% CI, 0.290.93) [42].

Positive coping style is problem-focused coping behavior directed at reducing or eliminating a stressor through the positive use of coping resources. In our study of 376 elderly diabetic patients, positive coping, as assessed by the 4-item questionnaire, was associated with a reduced incidence of stroke, after adjustment for age, sex, BMI, HbA1c, systolic blood pressures, total cholesterol, triglycerides, HDL cholesterol, smoking, and a history of ischemic heart disease $(\mathrm{HR}=4.2 ; 95 \% \mathrm{CI}$, 1.8-10.1) (unpublished data).

Perceived level of life enjoyment is a positive psychological 
condition that reflects the ability to engage pleasurably with the environment. In the Japan Public Health Center-Based Study of 88,175 Japanese people, all aged between 40 and 69 years and followed-up for a median of 12.0 years, Japanese men with a low perceived level of life enjoyment demonstrated increased risk of total stroke (HR=1.22; $95 \%$ CI, 1.01-1.47) and fatal stroke (HR=1.75; 95\% CI, 1.28-2.38) [43].

A positive attitude towards aging is somewhat an adaptation to aging. Good physical and emotional functioning, low depression, and great resilience are all associated with a positive attitude towards aging [44]. A positive attitude towards aging can be assessed as a subscale of the PGC morale scale; it is a 6-item questionnaire that addresses age-related physical health, happiness, positive value for life, meaningfulness, and positive thinking about aging. In the 3-year follow-up study of diabetic patients with a mean age of 75 years, the absence of a positive attitude towards aging was a significant predictor of stroke after the 9 conventional risk factors for atherosclerotic disease were considered ( $\mathrm{HR}=3.0$; 95\% CI, 1.3-7.2) [6]. In contrast, neither agitation nor lonely dissatisfaction affected incident stroke $(\mathrm{HR}=2.3$; 95\% CI, 0.81-6.5; and HR=2.1; 95\% CI, 0.74-6.1) [6].

\section{Sense of Coherence and Stroke}

Sense of coherence (SOC) is a marker of social stress adaptive capacity. Antonovsky found that SOC is one of the most important psychological traits in Holocaust survivors [45]. SOC consists of three dimensions: sense of comprehensibility, sense of manageability, and meaningfulness. The SOC scale may be a reliable, valid, and cross culturally applicable instrument measuring how people manage stressful conditions [46].

People with strong SOC have a high ability to cope with difficulties and social adversity [45]. Strong SOC is associated with psychological well-being and low mortality $[47,48]$. In the UK European Prospective Investigation into Cancer (EPIC)-Norfolk study of 20,629 participants aged 41-80 years, a strong SOC was associated with a reduced incidence of stroke after adjusting for covariates, including hostility, depression, social class, and education (HR=0.76; 95\% CI, 0.60-0.96) [49]. Although neither the presence nor the severity of social adversity was associated with stroke incidence, faster adaptation to adverse events was associated with a reduced incidence of stroke.

People with low socioeconomic status may have a weaker SOC because they cannot use generalized resistance resources against stressors enough to cope with social adversity. In fact, high family income was associated with a strong sense of coherence in unemployed nurses [50]. In contrast, poor condition in childhood could have less experience for the formation of strong SOC. Therefore, weak SOC might partly explain the association between low economic status and high incidence of stroke. However, SOC is strongly associated with psycho-emotional resources such as the quality of the relationship with partner, social support, quality of work, and childhood living conditions rather than socio-economic circumstances [51].

Therefore, in order to prevent the development of stroke, it may be more important to enhance protective psychological factors such as coping, positive attitude toward aging, and SOL, as well as to reduce feelings of negativity, like depression, discontent, hostility, and anger, and stressors (Figure 1).

\section{Psychological Factors and Atherosclerosis}

The mechanism by which stroke occurs as a result of psychological factors remains unknown. Psychosocial distress or depression may play an important role in the development of stroke due to an

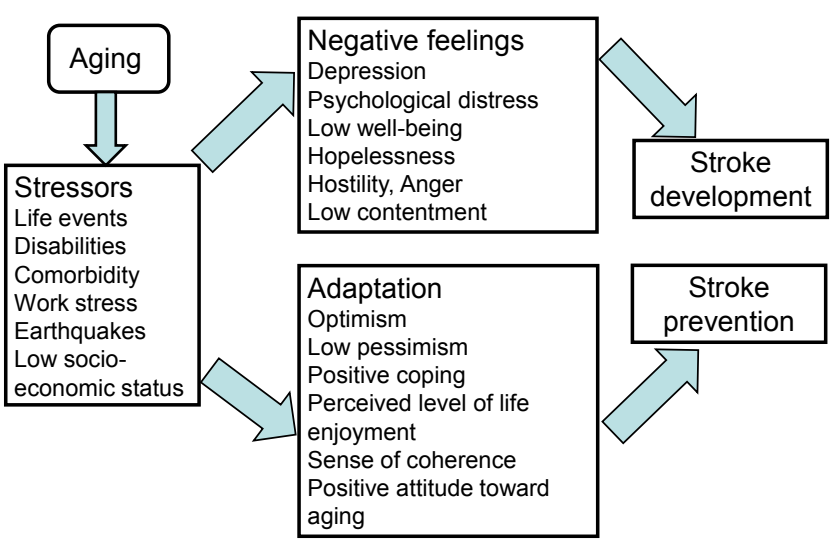

Figure 1: Psychological factors and stroke development or prevention.

increased activation of the hypothalamic-pituitary-adrenal axis, high cortisol, and high sympathetic nerve activity. For example, it has been demonstrated that psychosocial stress accelerates endothelial dysfunction and arteriosclerosis in monkeys [52,53]. In contrast, $\beta$-adrenergic blockers inhibit coronary atherosclerosis in monkeys exposed to psychosocial stress [54]. In the Chicago Community Adult Health Study, hopelessness, but not depression, was linearly associated with soluble intercellular adhesion molecule- 1 , which is an early marker of endothelial cell dysfunction [55]. Flow-mediate dilatation was impaired in patients treated for depression [56]. In contrast, antidepressant therapy using the selective serotonin reuptake inhibitor (SSRI), sertraline, improved the markers of platelet/endothelial activation, e-selectin, and beta-thromboglobulin in depressed patients after acute coronary syndrome [57].

Depression may induce activation of platelet activity, leading to the development of stroke. Indeed, it has been reported that platelet activity is increased in depressed patients [58]. In contrast, antidepressant agents such as SSRI inhibit the activation of platelet in patients with depression [59]. Platelet NOS activity and NO metabolite levels in the plasma of patients with depression are reported decreased, which may in turn account for the increased platelet activity observed in these patients, as well as the endothelial dysfunction [60].

An increased expression of inflammatory markers associated with psychological factors may be involved in the pathogenesis of atherosclerotic disease. It has been demonstrated that the inflammatory markers, C-reactive protein (CRP), IL-6, and IL- 1 are associated with depression in a community-based study of people with ischemic heart disease [61]. Higher levels of chronic stress have been associated with higher concentrations of IL-6 and CRP [62]; however, these associations disappeared once the following were controlled for: socioeconomic status, behaviors, BMI, and diabetes. In a study of 1,339 Japanese civil servants, a higher SOC was associated with lower serum CRP levels only in men [63].

With regard to life stress in older adults, emotional stress reportedly decreases cellular immune function, while high SOC has been associated with increased natural killer cell activity [64]. Exercise through health education also increases natural killer cell activity as well as SOC [65]. Immunomodulation by SOC might have a favorable effect on atherosclerosis.

\section{Sense of Coherence and Life-style Intervention}

For the prevention of stroke, how do we increase SOC in high- 
risk people? People with high SOC may obtain optimism because they have the capability to make social networks and to get the support they need from others. They may have the ability to cope skillfully with difficulties, such as psychological stressors that afflict patients with diabetes mellitus or patients at a high-risk of developing atherosclerotic disease. Therefore, a strategy for improving SOC may be of great use in terms of life-style interventions for the prevention of stroke.

Few intervention studies have been conducted to improve SOC for stroke prevention. The 12-month health intervention program, which consisted of study circles with diet sessions and physical activity in 41 patients with psychiatric disorder, increased SOC as well as physical health compared to the control group [66].

SOC affects life style choices that promote health. In a populationbased northern Sweden study of 4991 persons aged 25-74 years, women in the highest SOC quartile, measured by the 13-item Antonovsky questionnaire, had a higher intake of fruit and vegetables but a lower intake of energy, total and saturated fat, sucrose, and sweets [67]. Wainwright et al. investigated whether the association between high SOC and reduced mortality could be explained by lifestyle choices and socioeconomic status in the EPIC-Norfolk study. They found that approximately $23 \%$ of the association was intervened by lifestyle choices such as dietary intake of fruit, vegetables, and fiber, as well as physical activity, the cession of cigarette smoking, and socioeconomic status [68]. In a 5-year follow-up study of 110 middle-aged male office workers, low SOC was associated with weight gain as well as poor psychological well-being [69]. Individuals with low SOC, who find it difficult to cope with stress, tend to take in more fatty food and sweets or midnight snack, leading to weight gain.

In the Japan Diabetes Complications Study of 2033 type 2 diabetic patients aged 40-70 years, lifestyle modification, including dietary habits, physical activities, and adherence to treatment by telephone counseling and clinic visits, reduced the incidence of stroke; although, the status of conventional cardiovascular risk factors did not differ between the two groups [70]. Lifestyle intervention, including the construction of intense social networks by healthcare providers may have favorable effects on psychological factors like SOC. Cohen and Kanter examined the relationship between glycemic control and SOC, psychological distress, and adherence to self-care behavior in 67 people with diabetes [71]; a path analysis revealed that SOC was indirectly related to glycemic control through the adherence to self-care behavior and psychological distress. Thus, SOC could be an important target for psychological intervention in people with diabetes.

In conclusion, stressors, depression, and the other feelings of negativity are associated with incident stroke, while protective psychological factors against stressors such as optimism, positive coping style, a positive attitude towards aging, and SOC are associated with a reduced incidence of stroke. Further studies are required to understand the mechanism by which psychological factors influence the risk of stroke and atherosclerosis. Since SOC reflects the ability to cope with psychological stress and to tailor lifestyle choices for the promotion of health, a strategy focused on improving SOC could be an advantageous approach to intervening in lifestyle choices that increase the risk of stroke.

\section{References}

1. Costopoulos C, Liew TV, Bennett M (2008) Ageing and atherosclerosis: Mechanisms and therapeutic options. Biochem Pharmacol 75: 1251-1261.

2. Nagasawa SY, Okamura T, Iso H, Tamakoshi A, Yamada M, et al. (2012) Relation between serum total cholesterol level and cardiovascular disease stratified by sex and age group: a pooled analysis of 65594 individuals from 10 cohort studies in Japan. J Am Heart Assoc 1: e001974.

3. Zhao KX, Huang CQ, Xiao Q, Gao Y, Liu QX, et al. (2012) Age and risk for depression among the elderly: a meta-analysis of the published literature. CNS Spectr 17: 142-154.

4. Tsutsumi A, Kayaba K, Kario K, Ishikawa S (2009) Prospective study on occupational stress and risk of stroke. Arch Intern Med 169: 56-61.

5. Egido JA, Castillo O, Roig B, Sanz I, Herrero MR, et al. (2012) Is psychophysical stress a risk factor for stroke? A case-control study. J Neurol Neurosurg Psychiatry 83: 1104-1110.

6. Araki A, Murotani Y, Kamimiya F, Ito $\mathrm{H}$ (2004) Low well-being is an independent predictor for stroke in elderly patients with diabetes mellitus. J Am Geriatr Soc 52: $205-210$.

7. Kornerup H, Osler M, Boysen G, Barefoot J, Schnohr P, et al. (2010) Major life events increase the risk of stroke but not of myocardial infarction: results from the Copenhagen City Heart Study. Eur J Cardiovasc Prev Rehabil 17: 113-118.

8. Guiraud V, Touzé E, Rouillon F, Godefroy O, Mas JL (2012) Stressful life events as triggers of ischemic stroke: a case-crossover study. Int J Stroke.

9. Sokejima S, Nakatani Y, Kario K, Kayaba K, Minowa M, et al. (2004) Seismic intensity and risk of cerebrovascular stroke: 1995 Hanshin-Awaji earthquake. Prehosp Disaster Med 19: 297-306.

10. Kario K (2012) Disaster hypertension - its characteristics, mechanism, and management - . Circ J 76: 553-562.

11. Kirizuka K, Nishizaki H, Kohriyama K, Nukata O, Arioka Y, et al. (1997) Influences of The Great Hanshin-Awaji Earthquake on glycemic control in diabetic patients. Diabetes Res Clin Pract 36: 193-196.

12. Cox AM, McKevitt C, Rudd AG, Wolfe CD (2006) Socioeconomic status and stroke. Lancet Neurol 5: 181-188.

13. Addo J, Ayerbe L, Mohan KM, Crichton S, Sheldenkar A, et al. (2012) Socioeconomic status and stroke: an updated review. Stroke 43: 1186-1191.

14. Lazzarino Al, Hamer M, Stamatakis E, Steptoe A (2013) Low socioeconomic status and psychological distress as synergistic predictors of mortality from stroke and coronary heart disease. Psychosom Med 75: 311-316.

15. Feigin VL, Lawes CM, Bennett DA, Barker-Collo SL, Parag V (2009) Worldwide stroke incidence and early case fatality reported in 56 population-based studies: a systematic review. Lancet Neurol 8: 355-369.

16. Ferketich AK, Schwartzbaum JA, Frid DJ, Moeschberger ML (2000) Depression as an antecedent to heart disease among women and men in the NHANES I study. National Health and Nutrition Examination Survey. Arch Intern Med 160 1261-1268.

17. Ohira T, Iso H, Satoh S, Sankai T, Tanigawa T, et al. (2001) Prospective study of depressive symptoms and risk of stroke among japanese. Stroke 32: 903 908

18. Salaycik KJ, Kelly-Hayes M, Beiser A, Nguyen AH, Brady SM, et al. (2007) Depressive symptoms and risk of stroke: the Framingham Study. Stroke 38: 16-21.

19. Larson SL, Owens PL, Ford D, Eaton W (2001) Depressive disorder, dysthymia and risk of stroke: thirteen-year follow-up from the Baltimore epidemiologic catchment area study. Stroke 32: 1979-1983.

20. Pan A, Okereke OI, Sun Q, Logroscino G, Manson JE, et al. (2011) Depression and incident stroke in women. Stroke 42: 2770-2775.

21. Wulsin L, Alwell K, Moomaw CJ, Lindsell CJ, Kleindorfer DO, et al. (2011) Antidepressant medication use and future risk of cardiovascular disease: the Scottish Health Survey. Eur Heart J 32: 437-442.

22. Wulsin L, Alwell K, Moomaw CJ, Lindsell CJ, Kleindorfer DO, et al. (2012) Comparison of two depression measures for predicting stroke outcomes. $J$ Psychosom Res 72: 175-179.

23. Wouts L, Oude Voshaar RC, Bremmer MA, Buitelaar JK, Penninx BW, et al. (2008) Cardiac disease, depressive symptoms, and incident stroke in an elderly population. Arch Gen Psychiatry 65: 596-602.

24. Rutledge T, Linke SE, Olson MB, Francis J, Johnson BD, et al. (2008) Social networks and incident stroke among women with suspected myocardial ischemia. Psychosom Med 70: 282-287. 
25. Avendano M, Kawachi I, Van Lenthe F, Boshuizen HC, Mackenbach JP, et al (2006) Socioeconomic status and stroke incidence in the US elderly: the role of risk factors in the EPESE study. Stroke 37: 1368-1373.

26. Kim JM, Stewart R, Kim SW, Yang SJ, Shin IS, et al. (2008) BDNF genotype potentially modifying the association between incident stroke and depression. Neurobiol Aging 29: 789-792.

27. Surtees PG, Wainwright NW, Luben RN, Wareham NJ, Bingham SA, et al. (2008) Psychological distress, major depressive disorder, and risk of stroke. Neurology 70: 788-794.

28. May M, McCarron P, Stansfeld S, Ben-Shlomo Y, Gallacher J, et al. (2002) Does psychological distress predict the risk of ischemic stroke and transient ischemic attack? The Caerphilly Study. Stroke 33: 7-12.

29. Araki A, Ito H (2009) Diabetes mellitus and geriatric syndromes. Geriatr Gerontol Int 9: 105-114.

30. Black SA (1999) Increased health burden associated with comorbid depression in older diabetic Mexican Americans. Results from the Hispanic Established Population for the Epidemiologic Study of the Elderly survey. Diabetes Care 22: $56-64$.

31. Petterson T, Lee $P$, Hollis S, Young B, Newton P, et al. (1998) Well-being and treatment satisfaction in older people with diabetes. Diabetes Care 21 930-935

32. Araki A, Ito H (2003) Development of elderly diabetes burden scale for elderly patients with diabetes mellitus. Geriatr Gerontol Int 3: 212-224.

33. Araki A, Izumo Y, Inoue J, Takahashi R, Takanashi K, et al. (1995) Factors associated with increased diabetes burden in elderly diabetic patients. Nihon Ronen Igakkai Zasshi 32: 797-803.

34. Agewall S, Wikstrand J, Fagerberg B (1998) Stroke was predicted by dimensions of quality of life in treated hypertensive men. Stroke 29: 2329-2333.

35. Agewall S, Wikstrand J, Dahlö f C, Fagerberg B (1996) Negative feelings (discontent) predict progress of intima-media thickness of the common carotid artery in treated hypertensive men at high cardiovascular risk. Am J Hypertens 9: 545-550.

36. Whipple MO, Lewis TT, Sutton-Tyrrell K, Matthews KA, Barinas-Mitchell E, et al. (2009) Hopelessness, depressive symptoms, and carotid atherosclerosis in women: the Study of Women's Health Across the Nation (SWAN) heart study. Stroke 40: 3166-3172.

37. Everson-Rose SA, Lewis TT, Karavolos K, Matthews KA, Sutton-Tyrrell K, et al. (2006) Cynical hostility and carotid atherosclerosis in African American and white women: the Study of Women's Health Across the Nation (SWAN) Heart Study.152: 982.

38. Ohira T, Diez Roux AV, Polak JF, Homma S, Iso H, et al. (2012) Associations of anger, anxiety, and depressive symptoms with carotid arterial wall thickness: the multi-ethnic study of atherosclerosis. Psychosom Med 74: 517-525.

39. Rice SC, Zonderman AB, Metter EJ, Najjar SS, Waldstein SR (2009) Absence of relation between depressive symptoms and carotid intimal medial thickness in the Baltimore Longitudinal Study of Aging. Psychosom Med 71: 70-76.

40. Faramawi MF, Gustat J, Wildman RP, Rice J, Johnson E, et al. (2007) Relation between depressive symptoms and common carotid artery atherosclerosis in American persons $>$ or $=65$ years of age. Am J Cardiol 99: 1610-1613.

41. Kim ES, Park N, Peterson C (2011) Dispositional optimism protects older adults from stroke: the Health and Retirement Study. Stroke 42: 2855-2859.

42. Nabi H, Koskenvuo M, Singh-Manoux A, Korkeila J, Suominen S, et al (2010) Low pessimism protects against stroke: the Health and Social Support (HeSSup) prospective cohort study. Stroke 41: 187-190.

43. Shirai K, Iso H, Ohira T, Ikeda A, Noda H, et al. (2009) Perceived level of life enjoyment and risks of cardiovascular disease incidence and mortality: the Japan public health center-based study. Circulation 120: 956-963.

44. Kavirajan H, Vahia IV, Thompson WK, Depp C, Allison M, et al. (2011) Attitude Toward Own Aging and Mental Health in Post-menopausal Women. Asian J Psychiatr 4: 26-30.

45. Lindström B, Eriksson M (2006) Contextualizing salutogenesis and Antonovsky in public health development. Health Promot Int 21: 238-244.

46. Eriksson M, Lindström B (2005) Validity of Antonovsky's sense of coherence scale: a systematic review. J Epidemiol Community Health 59: 460-466.
47. Matsuzaki I, Sagara T, Ohshita Y, Nagase H, Ogino K, et al. (2007) Psychologica factors including sense of coherence and some lifestyles are related to general health questionnaire-12 (GHQ-12) in elderly workers in Japan. Environ Health Prev Med 12: 71-77.

48. Surtees P, Wainwright N, Luben R, Khaw KT, Day N (2003) Sense of coherence and mortality in men and women in the EPIC-Norfolk United Kingdom prospective cohort study. Am J Epidemiol 158: 1202-1209.

49. Surtees PG, Wainwright NW, Luben RL, Wareham NJ, Bingham SA, et al (2007) Adaptation to social adversity is associated with stroke incidence: evidence from the EPIC-Norfolk prospective cohort study. Stroke 38: 1447 1453

50. Leino-Loison K, Gien LT, Katajisto J, Välimäki M (2004) Sense of coherence among unemployed nurses. J Adv Nurs 48: 413-422.

51. Volanen SM, Lahelma E, Silventoinen K, Suominen S (2004) Factor contributing to sense of coherence among men and women. Eur J Public Health 14: 322-330.

52. Strawn WB, Bondjers G, Kaplan JR, Manuck SB, Schwenke DC, et al. (1991) Endothelial dysfunction in response to psychosocial stress in monkeys. Circ Res 68: 1270-1279.

53. Kaplan JR, Manuck SB, Clarkson TB, Lusso FM, Taub DM, et al. (1983) Socia stress and atherosclerosis in normocholesterolemic monkeys. Science 220 733-735.

54. Kaplan JR, Manuck SB, Adams MR, Weingand KW, Clarkson TB (1987) Inhibition of coronary atherosclerosis by propranolol in behaviorally predisposed monkeys fed an atherogenic diet. Circulation 76: 1364-1372.

55. Do DP, Dowd JB, Ranjit N, House JS, Kaplan GA (2010) Hopelessness, depression, and early markers of endothelial dysfunction in U.S. adults. Psychosom Med 72: 613-619.

56. Broadley AJ, Korszun A, Jones CJ, Frenneaux MP (2002) Arterial endothelia function is impaired in treated depression. Heart 88: 521-523.

57. Serebruany VL, Glassman AH, Malinin Al, Nemeroff CB, Musselman DL, et al. (2003) Sertraline AntiDepressant Heart Attack Randomized Trial Study Group. Platelet/endothelial biomarkers in depressed patients treated with the selective serotonin reuptake inhibitor sertraline after acute coronary events: the Sertraline AntiDepressant Heart Attack Randomized Trial (SADHART) Platelet Substudy. Circulation 108: 939-944.

58. Musselman DL, Tomer A, Manatunga AK, Knight BT, Porter MR, et al. (1996) Exaggerated platelet reactivity in major depression. Am J Psychiatry 153 1313-1317.

59. Markovitz JH, Shuster JL, Chitwood WS, May RS, Tolbert LC (2000) Platele activation in depression and effects of sertraline treatment: An open-labe study. Am J Psychiatry 157: 1006-1008.

60. Chrapko WE, Jurasz P, Radomski MW, Lara N, Archer SL, et al. (2004) Decreased platelet nitric oxide synthase activity and plasma nitric oxide metabolites in major depressive disorder. Biol Psychiatry 56: 129-134.

61. Howren MB, Lamkin DM, Suls J (2009) Associations of depression with C-reactive protein, IL-1, and IL-6: a meta-analysis. Psychosom Med 71: 171

62. Ranjit N, Diez-Roux AV, Shea S, Cushman M, Seeman T, et al. (2007) Psychosocial factors and inflammation in the multi-ethnic study of atherosclerosis. Arch Intern Med 167: 174-181.

63. Nasermoaddeli A, Sekine M, Kagamimori S (2006) Gender differences in associations of C-reactive protein with atherosclerotic risk factors and psychosocial characteristics in Japanese civil servants. Psychosom Med 68 58-63.

64. Lutgendorf SK, Vitaliano PP, Tripp-Reimer T, Harvey JH, Lubaroff DM (1999) Sense of coherence moderates the relationship between life stress and natura killer cell activity in healthy older adults. Psychol Aging 14: 552-563.

65. Nakamura H, Matsuzaki I, Sasahara S, Hatta K, Nagase H, et al. (2003) Enhancement of a sense of coherence and natural killer cell activity which occurred in subjects who improved their exercise habits through health education in the workplace. J Occup Health 45: 278-285

66. Forsberg KA, Björkman T, Sandman PO, Sandlund M (2010) Influence of a lifestyle intervention among persons with a psychiatric disability: a cluste randomised controlled trail on symptoms, quality of life and sense of coherence. J Clin Nurs 19: 1519-1528. 
Citation: Araki A, Ito H (2013) Psychological Risk Factors for the Development of Stroke in the Elderly. J Neurol Neurophysiol 4: 147. doi:10.4172/21559562.1000147

67. Lindmark U, Stegmayr B, Nilsson B, Lindahl B, Johansson I (2005) Food selection associated with sense of coherence in adults. Nutr $\mathrm{J} 4: 9$.

68. Wainwright NW, Surtees PG, Welch AA, Luben RN, Khaw KT, et al. (2008) Sense of coherence, lifestyle choices and mortality. J Epidemiol Community Health 62: 829-831.

69. Sagara T, Hitomi Y, Kambayashi Y, Hibino Y, Matsuzaki I, et al. (2009) Common risk factors for changes in body weight and psychological well-being in Japanese male middle-aged workers. Environ Health Prev Med 14: 319-327.
70. Sone H, Tanaka S, limuro S, Tanaka S, Oida K, et al. (2010) Japan Diabetes Complications Study Group. Long-term lifestyle intervention lowers the incidence of stroke in Japanese patients with type 2 diabetes: a nationwide multicentre randomised controlled trial (the Japan Diabetes Complications Study). Diabetologia 53: 419-428.

71. Cohen M, Kanter Y (2004) Relation between sense of coherence and glycemic control in type 1 and type 2 diabetes. Behav Med 29: 175-183. 